See discussions, stats, and author profiles for this publication at: https://www.researchgate.net/publication/224383824

\title{
Wave Parameters Estimated from Scatterometer Data
}

Conference Paper · August 2008

DOI: 10.1109/IGARSS.2008.4779998 · Source: IEEE Xplore

\section{CITATIONS}

0

3 authors:

\section{Jie Guo}

Chinese Academy of Sciences

22 PUBLICATIONS 151 CITATIONS

SEE PROFILE

W. Perrie

Bedford Institute of Oceanography, Fisheries and Oceans Canada 275 PUBLICATIONS 3,254 CITATIONS

SEE PROFILE

Some of the authors of this publication are also working on these related projects:

Hurricane Research with Synthetic Aperture Radar View project

Submesoscale Processes in SWOT/ SAR signals View project
Nanjing University of Information Science \& Technology 192 PUBLICATIONS 1,023 CITATIONS

SEE PROFILE 


\title{
WAVE PARAMETERS ESTIMATED FROM SACTTEROMETER DATA
}

\author{
Jie Guo ${ }^{1,2}$, Yijun $\mathrm{He}^{1}$ and William Perrie ${ }^{3}$ \\ ${ }^{1}$ Institute of oceanology, Chinese Academy of Sciences, Qingdao 266071, China \\ ${ }^{2}$ Graduate School of the Chinese Academy of Sciences, Beijing, 100039, China \\ ${ }^{3}$ Bedford Institute of Oceanography, Dartmouth, Nova Scotia, B2Y 4A2 Canada \\ heyj@ms.qdio.ac.cn
}

\section{INTRODUCTION}

It is well known that a good description of ocean wave conditions is very important for the safety of lives and structures at sea. Ocean waves are described by parameters such as significant wave height, wave period, and wave direction. Significant wave height represents mean wave height of the highest $33 \%$ waves in the energy distribution of a given ocean wave spectrum. In the past, ocean wave parameters were observed by wave gauges and buoys. However, it is impossible for these point measurement instruments to provide detailed wave information over very large basin areas or global oceans. This situation was changed when oceanic satellites were launched.

Until now, the synthetic aperture radar (SAR) is the only sensor that can be used to measure ocean wave spectra. However, because of the azimuthal wave cutoff and lack of power, it cannot measure the high frequency region of the wave spectra. Its application is therefore limited for ocean waves. Significant wave height $\left(\mathrm{H}_{1 / 3}\right)$ can be measured globally by satellite radar altimeter. It is inferred directly from the shape of the radar pulse returning to the nadir-looking altimeter, assuming Gaussian surface elevations. Moreover, wind speed is also retrieved from the RCS (radar scattering cross section) measured by altimeter. Hwang et al. [1] established the relation among wind speed, period and $\mathrm{H}_{1 / 3}$ using buoys in the Gulf of Mexico, estimating the wave periods from wind speeds and wave heights measured by altimeter. Although these wave parameters can be measured at $7 \mathrm{~km}$ resolution along the track, the two- dimensional spatial resolution is quite low, and the results are limited in applications.

Scatterometery is a specialized sensor that can be used to measure the sea surface wind vector, with a spatial resolution of $50 \mathrm{~km}$ or less. The accuracy in measured wind speeds is about $2 / \mathrm{ms}$. QuikSCAT can cover $98 \%$ of the global oceans twice each day and it has been applied widely. The principle of measuring wind vectors using scatterometery is that RCS depends on the wind vector. In fact, RCS represents the radar return intensity of the sea surface, as forced by wind. Ocean waves almost always include wind waves and swell. Therefore the RCS not only depends on wind vectors, but also on ocean waves. For the Tropical Rainfall Mapping Mission (TRMM) Precipitation Radar (PR) and two satellite altimeters, namely: 1) Jason1 and 2) ENVISAT, Tran et al. [2] shows that the RCS depends on the ocean waves and wind speed. In the next sections we describe our methodology, results and conclusions.

\section{METHODS AND RESULTS}

\subsection{The effect of ocean wave on the radar scattering cross section}

For the TRMM PR, Tran et al.[2] discussed the effect of significant wave height on RCS in detail. Their results are consistent with previous analysis at higher incidence angles $\left(20^{\circ}, 30^{\circ}, 40^{\circ}\right.$, and $\left.60^{\circ}\right)$ [3]. ERS-1/2 scatterometer data with NDBC buoy data are used to determine the relation between wave parameters and RCS. Figure 1 shows the relationship between RCS and relative azimuthal angle for an incidence angle of $55^{\circ}$ when the ratio between significant wave height and average period, $\mathrm{H}_{1 / 3} / \mathrm{T}$, is 0.25 . The relationship looks like that between RCS and wind. Thus, we can get a model for the relation between $\mathrm{H}$ or $\mathrm{H} / \mathrm{T}$ and $\mathrm{RCS}$. The blue dots are the results using our model and the red dots represent the buoy observation results (Figure 1).

\subsection{The retrieval algorithm of ocean wave parameters}

Significant wave height $\mathrm{H}_{1 / 3}$ and the ratio $\mathrm{H}_{1 / 3} / \mathrm{T}$ are retrieved from ERS-1/2 scatterometer data using a neural network algorithm. 


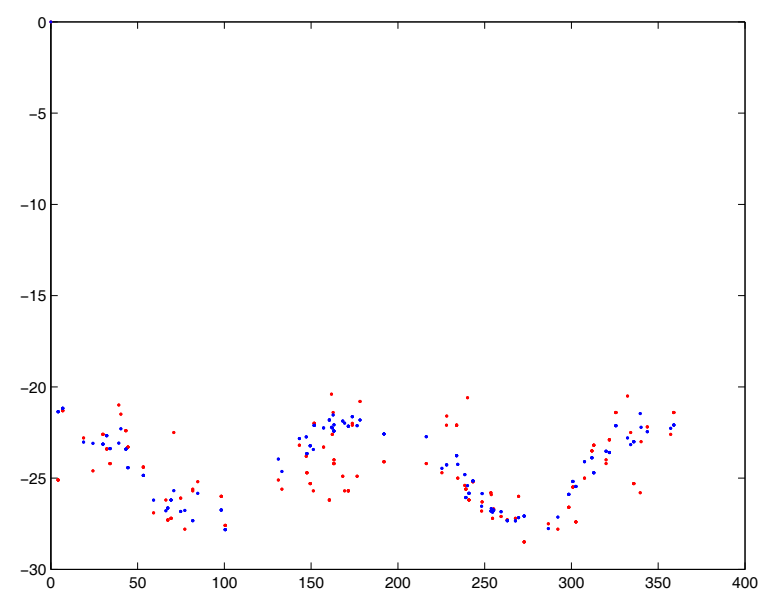

Figure 1 The relationship between $\mathrm{RCS}$ and relative azimuthal angle for incidence angle $55^{\circ}$ when the ratio between significant wave height $\mathrm{H}_{1 / 3}$ and average period, $\mathrm{H}_{1 / 3} / \mathrm{T}$, is 0.25 . $\mathrm{X}$-axis is relative wind direction, $\mathrm{Y}$-axis is $\mathrm{RCS}$ in $\mathrm{dB}$

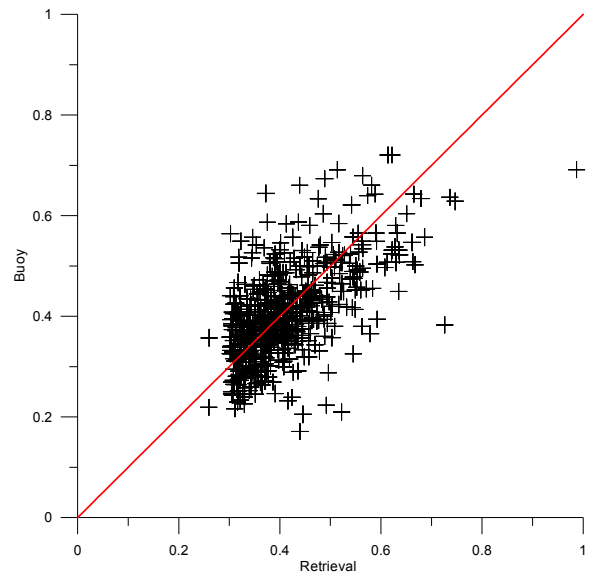

The ratio between significant wave height and average wave period

Figure 2 Comparison of the ratio between significant wave height and average wave period between buoy data and retrieved values from ERS-1/2 scatterometer data. X-axis is the $\mathrm{H}_{1 / 3} / \mathrm{T}$ retrieved from ERS- 1 scatterometer, $\mathrm{Y}$-axis is the $\mathrm{H}_{1 / 3} / \mathrm{T}$ from buoy.

\subsection{The comparison of wave parameters retrieved with observed by buoy}

In Figure 2, the comparison of $\mathrm{H}_{1 / 3} / \mathrm{T}$ between buoy data and retrieved values from ERS-1/2 scatterometer data are shown. The bias, average absolute error and root mean square of the $\mathrm{H}_{1 / 3}$ and $\mathrm{H}_{1 / 3} / \mathrm{T}$ retrievals with these measured values by buoy are $0.004 \mathrm{~m}, 0.50 \mathrm{~m}, 0.70 \mathrm{~m},-0.002 \mathrm{~m} / \mathrm{s}, 0.053 \mathrm{~m} / \mathrm{s}$ and $0.07 \mathrm{~m} / \mathrm{s}$, respectively.

\section{CONCLUSIONS}

A model to retrieve oceanic wave parameters is established using ERS-1/2 scatterometer data and NDBC buoy wave data. Results suggest that ocean waves can be measured by scatterometers. The bias, average absolute error and root mean square error of the $\mathrm{H}_{1 / 3}$ and $\mathrm{H}_{1 / 3} / \mathrm{T}$ retrievals, compared to values measured by buoys, are $0.004 \mathrm{~m}, 0.50 \mathrm{~m}, 0.70 \mathrm{~m},-0.002 \mathrm{~m} / \mathrm{s}$, $0.053 \mathrm{~m} / \mathrm{s}$ and $0.07 \mathrm{~m} / \mathrm{s}$, respectively.

\section{ACKNOWNLODGYMENT}

This work was partly supported by the (China) national high technology projects under Grant 2008AA09Z102.

\section{REFERENCES}

[1] Hwang, P. A., W. J. Teague, G. A. Jacobs and D. W. Wang, A statistical comparison of wind speed, wave height, and wave period derived from satellite altimeters and ocean buoys in the Gulf of Mexico region, Journal of Geophys. Res., Vol. 103(C5), pp1045110468, May, 1998.

[2] Tran, N., B. Chapron, and D. Vandemark, Effect of Long Waves on Ku-Band Ocean Radar Backscatter at Low Incidence Angles Using TRMM and Altimeter Data, IEEE Geosci. \& Remote Sensing Lett., Vol. 4, No. 4, pp. 542-546, October 2007

[3] Nghiem, S. V., K. Li, S. H. Lou, G. Neumann, R. E. McIntosh, S. C. Carson, J. R. Carswell, E. J. Walsh, M. A. Donelan, and W. M. Drennan, "Observations of ocean radar backscatter at $\mathrm{Ku}$ and $\mathrm{C}$-bands in the presence of large waves during the surface wave dynamics experiment," IEEE Trans. Geosci. Remote Sens., vol. 33, no. 3, pp. 708-721, May 1995. 